Yan Jiang*

\title{
Ways of expressing counterfactual conditionals in Mandarin Chinese
}

https://doi.org/10.1515/lingvan-2019-0009

Received May 25, 2018; accepted April 3, 2019

\begin{abstract}
This paper discusses the ways in which Mandarin Chinese expresses counterfactual conditionals, and endeavours to motivate and theorize the use of such strategies. I aim to give an overall picture of Mandarin Chinese counterfactual conditionals, a topic which has hitherto not been covered in the Chinese linguistic literature. The strategies identified are the use of special lexicalized chunks to directly encode counterfactual meaning; the creation of tense mismatch and the accompanying counterfactual meaning, either through the use of relative tense pointing toward a hypothetical past event, or through the use of some special time adverbs; and the use of pure inference over conditionals with impossible or absurd antecedents. Overlaying these strategies is the presence of context-dependent simplifications, which may prompt the language user to omit the defining features of a given strategy.
\end{abstract}

Keywords: counterfactual; conditional; Mandarin Chinese; inference

\section{Introduction}

Counterfactual conditionals (henceforth $\mathrm{CF}$ ) are conditional sentences whose antecedents express meaning that is known to be contrary to fact or impossible to be true. In Indo-European languages, CFs have been treated as a predominantly grammatical, not lexical, phenomenon. How they are expressed in isolating languages such as Chinese is a less explored topic. Are CFs expressed more by lexical terms in Chinese? Can some lexical terms be taken as the outcome of grammaticalization, hence having grammatical functions as well? Is it even possible to define the boundary between grammatical and lexical phenomena in an isolating language? Our study on Chinese CFs to be reported here shows that lexical terms do have grammatical functions, or at least their roles can be explained in grammatical terms.

Studies on Chinese CF began with the controversial claim by Bloom (1981) that Mandarin Chinese lacks linguistic schemata for encoding $\mathrm{CF}$ with the result that Chinese $\mathrm{CFs}$ are comprehended as such purely with reference to contextual and contingent information. However, Chen (1988) identifies a cluster of lexical and grammatical features that often accompany conditionals with CF interpretations. Since his study is mainly descriptive, no principled explanations are offered as to when some features occur and when they do not. Jiang (2000), Jiang (2019), Wang and Jiang (2011), and Wang (2013) build on Chen (1988) in sharpening and enriching the data and give more systematic semantic descriptions on the nature of the contributing weak features to CF meaning as well as providing pragmatic accounts of the context-dependent factors that affect the reach of CF. Jiang and Wang (2016) and Jiang (2019) also discuss the use of special linguistic schemata for the expression of CF in Chinese dialects other than Mandarin, with special reference to Shanghainese. Yong (2016) and Jing-Schmidt (2017) provide statistical and corpus-based studies on the co-occurrence of some identified features with CF meaning, which lend support to the major claims of Chen (1988), Jiang (2000), Wang and Jiang (2011) and Wang (2013) that there do exist several linguistic strategies in expressing CF reasoning in Chinese.

*Corresponding author: Yan Jiang, Department of Linguistics, School of Languages, Cultures and Linguistics, SOAS, University of London, London, UK, E-mail: yj9@soas.ac.uk. https://orcid.org/0000-0002-7778-9543 
This paper aims at motivating and theorizing the use of such strategies with the goal of depicting an overall picture of CF conditionals for Mandarin Chinese within the typological framework of CFs for all languages proposed in Karawani (2014). Building mainly on my previous studies, I present four strategies of CF structures. I then present further cases involving context-dependent simplifications, which can be viewed as variants of the first four.

\section{CF chunks}

As observed in Karawani (2014), any language can express unequivocal CF meaning by using some lexicalized chunks that directly encode such a meaning. This is the case in many Chinese languages. In Mandarin, two special chunks, i.e. fixed phrasal expressions, can be used to lead a CF antecedent, one is yaobushi 'if-not-be' and the other is zaozhidao 'early-know'.

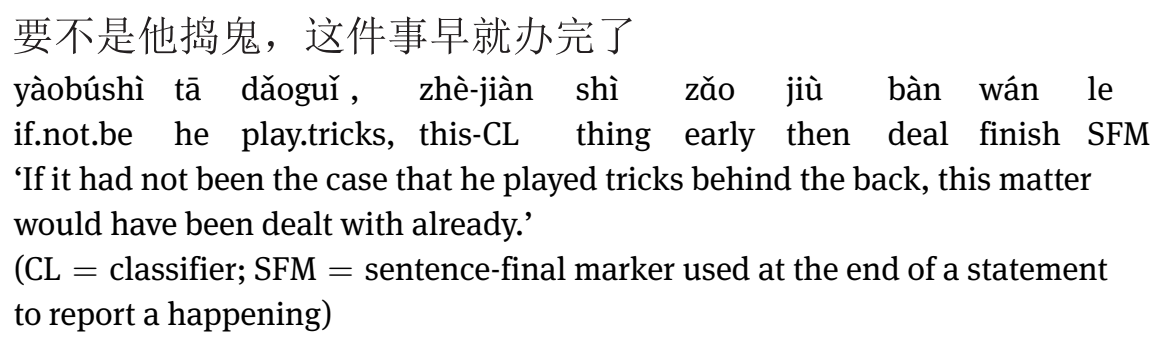

要不是听你说, 我还不知老邓的工厂关门的前因后果呢!

yàobúshì tīng nǐ shuō, wǒ hái bú zhī Lăo Dèng de

If.not.be hear you say, I still not know Old Deng MOD gōngchăng guānmén de qiányīnhòuguǒ ne !

factory close.down MOD reason SFM

'If it had not been the case that I learnt it from you, I would not have known the reason for Old Deng's factory to close down.'

$(\mathrm{MOD}=$ modifying marker $)$

(3)

早知道会迷路, 老子就不来这荒山野岭了!
zaozhīdào huì mílù, laozi jiù bu lái zhè huāngshānyěling le!
know.early will lose.way I then not come this wild.place
'Had I known I would lose my way, I would not have come to this wild place!'

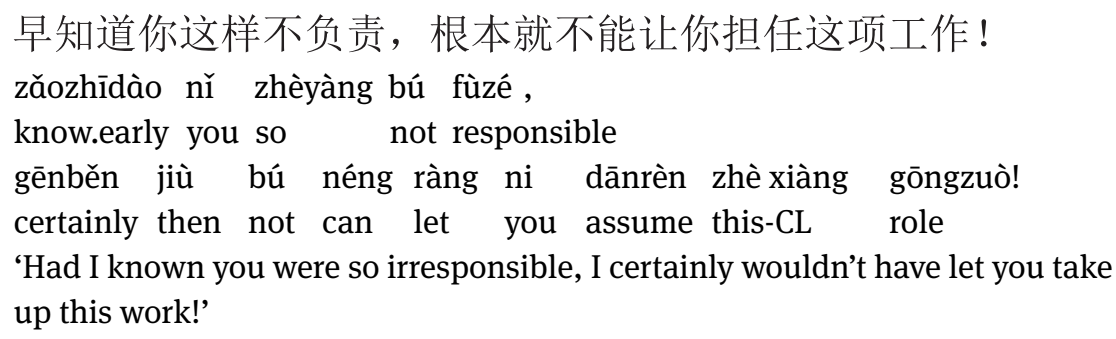

As lexicalized chunks, yaobushi and zaozhidao, when leading the antecedent of a conditional, most often express CF meaning, with some exceptional cases carrying their compositional meaning of 'If that is not the case ' and 'I know it early', which contexts easily disambiguate. Similar lexicalized chunks can be found in many other Chinese languages, although each single language may only have a handful. Examples in other Chinese languages are discussed in Jiang and Wang (2016) and Jiang (2019). Chunks provide the most direct means for expressing CF conditionals or optatives with CF meaning, the latter being statements expressing 
desire or regret. Yaobushi is an exemplary case of negative conditionals in the sense of Ippolito and $\mathrm{Su}$ (2014), with a negative element in the COMP domain and obligatorily CF. The nature of zaozhidao will be discussed in Section 4. But the meanings that can be expressed by yaobushi and zaozhidao are somewhat limited. In the yaobushi case, what follows the yaobushi chunk has to be a veridical proposition, that is, a proposition that is true, and the whole antecedent forms a negative context: a clause in the negation scope of yaobushi. This makes it difficult to embed some abstract proposition into the schema, even harder if the proposition following yaobushi is itself an explicitly negated or doubly negated proposition. In the case of zaozhidao, the antecedent has to be a first-person perspective, again imposing constraints on what can enter into this schema. Therefore, what is available as the very few possible deterministic CF markers in Mandarin cannot serve as all-purpose encoders of CF meaning. Surprisingly, Bloom (1981) makes no mention of such constructions, even though he rightly points out that conditionals containing yaoburan 'if not so' are indicative conditionals. More discussions can be found in Jiang (2019).

\section{Relative tense}

Chinese is sometimes described as a tenseless language in that it has no obligatory inflection marking overt absolute tense (Lin 2012). However, as proposed by Comrie (1985), a language may not have absolute tense to indicate past, present and future, but it may have relative tense to indicate prior or posterior temporal relationships, and relative tense can be realized by aspect markers. This is the case for Mandarin, which uses two optional verb suffixes, le and guo, as aspect markers to encode [+completion] and [+experienced], respectively. In conditionals, $l e$ and guo function as grammatical features that have a role in expressing the $\mathrm{CF}$ meaning. If we take conditionals without such verb suffixes as indicative conditionals by default, such conditionals are typically irrealis, being hypothetical in nature. But when le and guo as realis aspectual markers are used in conditionals contextually anchored to the present time, they can point toward a hypothetical past event. A tense mismatch occurs, leading to the exclusion of actual world, in the sense of Karawani (2014), which is the hallmark of CF meaning, as shown in (5) and (6).

$$
\begin{aligned}
& \text { 如果有了电, 灯就会亮了 } \\
& \text { rúguǒ yǒu-le diàn, dēng jiù huì liàng le } \\
& \text { If have-ASP electricity, light hence will be.on SFM. }
\end{aligned}
$$

'If there were electricity, light(s) would be on.'

(ASP $=$ aspectual suffix)

$$
\begin{aligned}
& \text { 要是你去过他家, 就不会不注意他那漂亮的太太的。 } \\
& \text { yàoshì nǐ qù-guò tā jiā } \\
& \text { if you go-ASP his home, } \\
& \text { jiù bù huì bú zhùyì tā nà piàoliàng de tàitài de } \\
& \text { hence not will not notice he that pretty MOD wife AM } \\
& \text { 'If you had been to his home, you would not fail to notice his pretty wife.' } \\
& \text { (AM = assertion marker) }
\end{aligned}
$$

But the contribution to CF made by such aspect markers is at best subtle and is by no means deterministic in expressing CF meaning. Hence their role has not been well identified. Adding to the complexity is the observation that when a conditional refers to a past eventuality yet omits to use le and guo, which often co-occur with past eventuality, a CF reading can also be perceived because there is again a tense mismatch and the accompanying actual-world-exclusion effect. An example is given as (7). ${ }^{1}$

1 Examples (5) and (7) are first discussed in Chen (1988), who noted that they can receive CF readings but did not provide theoretical explanation. Cf. also Jiang (2000), Wang (2013) and Jiang (2019) for some initial theoretical accounts. 
There are some other lexicalized expressions to make the CF meaning more explicit. One of these is the adverb zhende 'really'. When applied to a predicate in a statement sentence, zhende really means 'really', expressing a high degree of confirmation. But when used in a conditional antecedent, the proposition containing $z$ hende gives the implicature that at the time of speaking, the eventuality described has not had its truth established. That is to say, zhende implicates it is not yet the case that $\mathrm{P}$ or it has not yet been established that it is the case that P. So the use of zhende adds weight to the reach of CF interpretation, even though it does not deterministically encode CF meaning. (10) and (11) are relevant cases, showing the contribution that $z$ hende makes to the attainment of CF meaning is at best an implicature, not an entailment meaning.

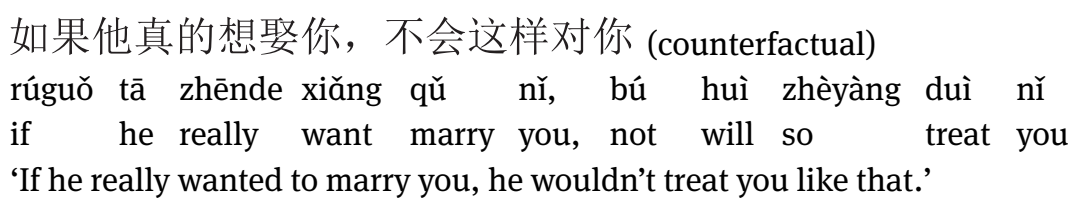

不要试图改变一个人, 如果他真的爱你, 他会按你说的去做的 (open
conditional)
bú yào shìtú gǎibiàn yī-gè $\quad$ rén, rúguǒ tā zhēnde ài nì
not will try change one-CL person if
tā huì àn he really love you
he will according.to you say MOD go do AM
'Don't try to change a person. If he really loves you, he will do what you say.'

Lexicalized features are used to enhance the CF meaning, as described in Karawani (2014). As they are usually optional, they are also called weak features by Wang and Jiang (2011) and Wang (2013).

\section{Pure inference}

In addition to the above three types of CF-production strategies, a special type of marker-free CF conditionals can be found in Mandarin: those with impossible or absurd antecedents, as shown in (12)-(14).

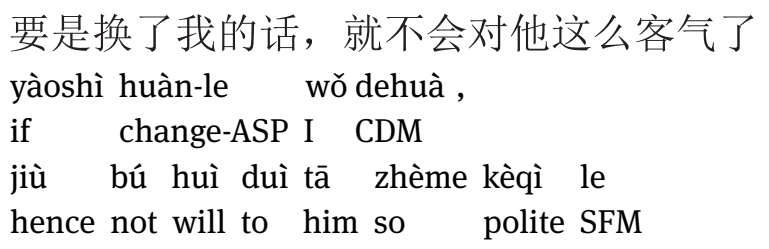

$$
\begin{array}{lllllll}
\multicolumn{1}{l}{\text { 如果太阳从西边出来, 我一定嫁给你。 }} \\
\text { rúguǒ tàiyáng } & \text { cóng xībiān chūlái, wǒ yīdìng jià gěi nì } \\
\text { if } & \text { sun } & \text { from west come.out, I } & \text { certainly marry to you }
\end{array}
$$

'If the sun came out from the west, I would certainly marry you.'

In the two example sentences above, the contradictory nature of the meaning in the antecedents makes the $\mathrm{CF}$ reading clear. There can even be conditionals in Mandarin that yield the CF readings in context without carrying contradictory antecedents. Given salient contextual information, a conditional can contain an antecedent that is known to be contrary to fact, with no use of any special strategies introduced above. Such a conditional can be indistinguishable from open conditionals, but is meant to be comprehended as CF. (14) is a case in point. 


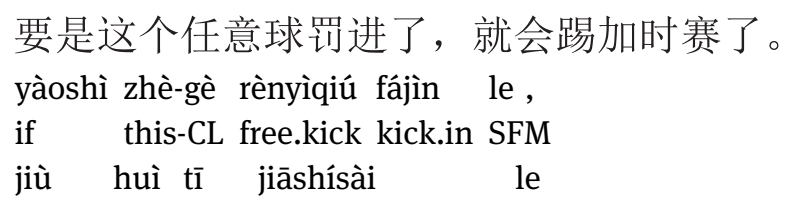

$a$. 'If this free-kick is in, the match will go into extra time.'(indicative conditional, uttered before the freekick)

$b$. 'If this free-kick were in, the match would go into extra time.'(counterfactual conditional, uttered when the free-kick did not score a goal)

Another relevant example from Mandarin is given here as (15), in which the existential construction in the antecedent can have a tenseless interpretation, and the CF meaning is inferred on the basis of knowledge of history, which resolves the apparent ambiguity between a CF reading and an open conditional reading.

没有共产党就没有新中国。
méi you gònghăndăng jiù méi yǒu xīn zhōngguó
not have communist.party then not have new China
'Without the Communist Party, then there will be no new China.'

Such examples seem to lend support to the view that CFs in Mandarin are often perceived through contextbased inference. Indeed, of the four strategies discussed so far, all the markers, chunks, suffixes and words, can be omitted, and the sentence could still be a CF. If contextual information is salient, CF meaning can be expressed and comprehended by means of open conditionals. But Mandarin CFs are solely context-reliant only when contextual information suffices to point to an unequivocal CF reading. If contextual information is felt to be insufficient in establishing the mutually manifest falsehood of the antecedent, the language user has other means to express CFs, in ways explicit or subtle.

For Chinese language users, context indeed most often suffices to help them determine if CF meaning is intended. This relates to one peculiar feature of Chinese CF conditionals. Bloom rightly observes that the Chinese usually make use of counterfactual speech and thought in concrete situations, "in which the negation facts are known or can be inferred" (Bloom 1981: 19ff.). "Within a concrete situational context which negates its premise," argues Bloom, "[a sentence] can be used to express a CF thought, even though there is no explicit linguistic marking in the sentence to signal that it is to be understood in that way". This explains why many Chinese CF conditionals are not felt to carry CF features or markers.

Acknowledgements: My thanks go to Dr. Mingya Liu for her great efforts in organizing the workshop on conditionals where this paper was presented in its initial form and for her work in editing this volume. Thanks also go to the two anonymous reviewers whose comments led to substantive revisions and improvements. Finally, great thanks go to Angela Terrill, the copy-editor, for her expert comments on the content and for her skilful work in improving on the English language.

\section{References}

Bloom, Alfred H. 1981. The linguistic shaping of thought: A study in the impact of language on thinking in China and the West. Hillsdale, NJ: Lawrence Erlbaum Associates. New print by NY, NY \& East Sussex, UK: Psychology Press, 2014.

Chen, Guohua. 1988. Yīng hàn jiashè tiáojiàn jù bijiào [A comparison between English and Chinese hypothetical conditionals]. Foreign Language Teaching and Research 73. 10-19.

Comrie, Bernard. 1985. Tense. Cambridge, UK: Cambridge University Press.

Ippolito, Michela \& Julia Su. 2014. Counterfactuals, negation and polarity. In Luka Crnič \& Uli Sauerland (eds.), The art and craft of semantics: A festschrift for Irene Heim, 70. 225-243. Vol. 1, MIT working papers in linguistics. 
Jiang, Yan. 2000. Hànyǔ tiáojiàn jù de wéishí jiěshì [On the counterfactual reading of Chinese conditionals]. In Bojiang Zhang (ed.), Studies and investigations on Chinese grammar, 257-279. Beijing: The Commercial Press.

Jiang, Yan. 2019. Chinese and counterfactual reasoning. In Chu-Ren Huang, Zhuo Jing-Schmidt \& Barbara Meiserernst (eds.), The Routledge handbook of Chinese applied linguistics, 276-293. Abingdon, Oxford \& New York: Routledge.

Jiang, Yan \& Yuying Wang 2016. Counterfactual subjunctive assertions in Shanghai dialect. In Andy C.-0. Chin, Bit-chee Kwok \& Benjamin K. Tsou (eds.) Commemorative essays for Professor Yuen Ren Chao: Father of modern Chinese linguistics, 193-201. Taipei: The Crane Publishing.

Jing-Schmidt, Zhuo. 2017. What are they good for? A constructionist account of counterfactuals in ordinary Chinese. Journal of Pragmatics 113. 30-52.

Karawani, Hadil. 2014. The real, the fake, and the fake fake: In counterfactual conditionals, crosslinguistically. Utrecht: LOT. Lin, Jo-wang. 2012. Tenselessness. In Robert I. Binnick (ed.) The Oxford handbook of tense and aspect, 669-695. Oxford University Press.

Wang, Yuying. 2013. The ingredients of counterfactuality in Mandarin Chinese. Beijing: China Social Science Press.

Wang, Yuying \& Yan Jiang. 2011. Hànyǔ wéishí yì de gòuchéng yīnsù [The ingredients of counterfactuality in Chinese]. In Yan Jiang (ed.) Approaching formal pragmatics, 366-412. Shanghai Educational Publishing House.

Yong, Qian. 2016. A corpus-based study of counterfactuals in Mandarin. Language and Linguistics 17(6). 891-915. 